\title{
Dictionary-derived Term
}

National Cancer Institute

\section{Source}

National Cancer Institute. Dictionary-derived Term. NCI Thesaurus. Code C82977.

The literal identifier of a thing as determined by a standards organization. 